\title{
Characterization of the ecophysiological responses of three pomegranate cultivars to salinity
}

\author{
A. OLMO ${ }^{*}$, F. GARCIA-SANCHEZ ${ }^{* *,+}$, I. SIMON*, V. LIDON* ${ }^{*}$, M. ALFOSEA-SIMON**, \\ J.M. CAMARA-ZAPATA* ${ }^{*}$ J.J. MARTINEZ-NICOLAS ${ }^{*,+}$, and S. SIMON-GRAO ${ }^{* *}$ \\ School of Engineering of Orihuela, University of Miguel Hernández, Ctra. de Beniel, km 3.2, Orihuela, \\ Alicante, Spain* \\ Centre of Edaphology and Applied Biology of Segura, CEBAS-CSIC, University Campus of Espinardo, \\ 30100 Espinardo, Murcia, Spain ${ }^{* *}$
}

\begin{abstract}
In order to understand photosynthetic responses of pomegranate plants (Punica granatum L.) to salinity, an experiment was conducted with three varieties, 'Mollar de Elche', 'Valenciana', and 'Wonderful', irrigated with seven salt concentrations $(0,40,60,80,100,120$, and $140 \mathrm{mM} \mathrm{NaCl})$. At the end of the experiment, parameters of gas exchange, chlorophyll fluorescence, water relations, and sugar and chloride concentrations were measured in leaves. As the concentration of $\mathrm{NaCl}$ increased, the concentration of $\mathrm{Cl}^{-}$in leaves was elevated, and the $\mathrm{CO}_{2}$ assimilation rate, stomatal conductance, variable fluorescence/maximum fluorescence ratio, PSII quantum yield, and total soluble sugars decreased. In 'Valenciana', the decrease of the net assimilation of $\mathrm{CO}_{2}$ could occur due to the closure of stomata, while in 'Mollar' and 'Wonderful', this was due to damage caused by $\mathrm{Cl}^{-}$toxicity. The study of carbohydrates also suggests a different behavior of carbon metabolism in the three varieties.
\end{abstract}

Additional key words: chloride toxicity; fruit tree; oxidative stress; photosynthesis; sodium toxicity; water stress.

\section{Introduction}

Pomegranate (Punica granatum L.) is a very interesting fruit tree for arid and semiarid areas in any part of the world, as it adapts well to every type of soil and climates found in these regions. In the southeast of Spain, these trees are able to grow in poor soils and climates, and are frequently cultivated with other fruit trees, such as figs (Ficus carica L.) and date palms (Phoenix dactylifera L.), which are also resistant to drought, salinity, iron chlorosis, and active limestone (Melgarejo 1993). Nevertheless, studies have shown that under hypoxia and anoxia conditions, the growth of pomegranate trees is significantly affected, as a result of the water relations and parameters of gas exchange being affected (Olmo-Vega et al. 2017).

On the eastern side of Spain, the scarcity of good quality water, due to the lack of precipitation (Köppen-Geiger climate classification: BSh; annual rainfall of $344 \mathrm{~mm}$ ), creates salinity problems in agricultural soils. Faced with the lack of water, the growers are obliged to use water from subterranean aquifers that have a high concentration of soluble salts, mainly $\mathrm{NaCl}$. In Spain, it is estimated that almost $3 \%$ of its arable land (3.5 million hectares) is seriously affected by salinity, resulting in damage to agricultural production, while $15 \%$ of this surface is in serious risk of salinization (Stolte et al. 2015).

The negative effects caused by salinity on crops can be mainly summarized in two factors: the osmotic effect and the toxic effect, although in some cases, nutritional alterations can be also observed (Parihar et al. 2015). Depending on the soil salinity, the exposure time of the plants to salinity, and the cultivar, one or the other factor can be given, or the combination of both. The osmotic effect refers to the salinity of the soil impeding the uptake of water by roots as it is retained by salts in the soil, resulting in alterations in the water status of plants, leading to the dehydration of tissues (Shabala and Munns 2017). This is one of the first visible symptoms when plants are watered with saline water, together with observed decrease in the elongation rate of leaves, due to changes in the water status of the cells. The other previously mentioned effect is toxicity, and it refers to the negative effects caused

\footnotetext{
Received 31 October 2018, accepted 24 July 2019.

${ }^{+}$Corresponding author; email: fgs@cebas.csic.es (F. Garcia-Sanchez), juanjose.martinez@umh.es (J.J. Martinez-Nicolas)

Abbreviations: DM - dry mass; $C_{\mathrm{i}}-$ intercellular $\mathrm{CO}_{2}$ concentration; $E$ - transpiration rate; $\mathrm{F}_{\mathrm{v}}{ }^{\prime} / \mathrm{F}_{\mathrm{m}}{ }^{\prime}-$ antennas efficiency in the PSII reaction centers; $g_{\mathrm{s}}-$ stomatal conductance; $P_{\mathrm{N}}-$ net photosynthetic rate; $\mathrm{q}_{\mathrm{P}}$ - photochemical quenching; RS - reducing sugars; RWC - relative water content; TNC - total nonstructural carbohydrates; TSS - total soluble sugars; $\Phi_{\mathrm{PSI}}$ - photochemical efficiency of PSII; $\Psi_{w}$ - leaf water potential.

Acknowledgements: The authors are grateful to the Project on Genetic Resources, Preservation of Endangered Species: Pomegranate and Quince (RFP2012-00009-00-00), funded by INIA-MINECO and FEDER, for the maintenance of the pomegranate tree and quince collection in which this study was performed.
} 
by the high concentration of $\mathrm{Cl}^{-}$and $\mathrm{Na}^{+}$in the plant tissues, especially in leaves. Despite the essential nature of $\mathrm{Cl}^{-}$as a nutrient in higher plants and $\mathrm{Na}^{+}$as a mineral nutrient for many halophytes and some $\mathrm{C}_{4}$ species, the concentrations of both ions in saline soils clearly exceeds the concentrations of the other nutrients, which results in their accumulation in the plant's tissues, causing toxicity, thereby affecting the correct functioning of plants at the physiological and metabolic levels, among others effects (Shabala and Munns 2017).

It is known that Spanish varieties of pomegranate trees are very tolerant to irrigation with saline water; however, there is a lack of research on the effects of salinity at the physiological level, specifically on the parameters of gas exchange, chlorophyll (Chl) fluorescence, water relations, and concentration of sugars, all of which are used to determine the physiological status of the plants (Ashraf and Harris 2013). According to Sun et al. (2018), pomegranate plants are very tolerant to saline water irrigation up to an EC of $15 \mathrm{dS} \mathrm{m}^{-1}$. In the Iranian varieties 'Malas' and 'Shishe', it has been shown that when the salinity in the irrigation water increased from 1.05 to 4.61 and $7.46 \mathrm{dS} \mathrm{m}^{-1}$, relative water content, stomatal conductance, total Chl, sugars, and Chl fluorescence parameters decreased (Khayyat et al. 2014, 2016). OkhovatianArdakani et al. (2010) observed different levels of salinity tolerance in a study with ten Iranian cultivars of pomegranate watered with 4,7 , and $10 \mathrm{dS} \mathrm{m}^{-1}$; however, the differential responses were not directly related to the accumulation of $\mathrm{Cl}^{-}$and/or $\mathrm{Na}^{+}$in the leaves. This suggests that the variations in the salinity tolerance between the pomegranate cultivars could depend on complex adaptation mechanisms acquired through time.

It is known that the variety 'Wonderful', one of the most popular varieties in southeastern Spain, is very tolerant to salinity, as it has mechanisms that mitigate the negative effects of this stress, thereby maintaining the normal water content, $\mathrm{Chl}$ fluorescence, and the activity of certain enzymes under high $\mathrm{NaCl}, \mathrm{KCl}$ or $\mathrm{Na}_{2} \mathrm{SO}_{4}$ salt treatments (Mastrogiannidou et al. 2016). However, little is known about the physiological response to salinity of the cultivars 'Mollar' and 'Valenciana', two of the most popular native cultivars in southeastern Spain. Thus, the objective of the present work was to understand the responses of pomegranate cultivation to salinity, in order to elucidate the possible mechanisms of adaptation of these plants to adverse conditions. A three-tier study was planned: 1) physiological: to characterize gas exchange, chlorophyll fluorescence, and water relations; 2) nutritional: to know the accumulation of chloride in leaves; and 3) biochemical: to study the primary $\mathrm{C}$ metabolism related with sugars (total soluble sugars, reducing sugars, and starch).

\section{Materials and methods}

Plant material and growing conditions: Pomegranate plants (Punica granatum L.) were obtained in a commercial nursery through woody cuttings, which were performed 11 months after the start of the assay. In total, 126 plants were used, 42 from each variety ('Mollar', 'Valenciana', and 'Wonderful'), which were approximately $15-20 \mathrm{~cm}$ in height. These plants were transplanted to $3.5-\mathrm{L}$ pots which contained a substrate composed of peat, coconut fiber, and perlite (5:4:1, Universal Substrate, Compost Reciclables, Murcia, Spain). The experiment was conducted from the middle of May to the last week of June in 2016, in a multitunnel greenhouse in the experimental field 'Tres Caminos', belonging to the Center of Edaphology and Applied Biology of the Segura (CEBAS-CSIC) in the municipality of Santomera (Murcia, Spain). To control the temperature, a cooling system was used (Novedades Agrícolas, Murcia, Spain), which maintained the temperature under $30^{\circ} \mathrm{C}$ in the summer, and the control of humidity was managed with humidification equipment equipped with an air compressor (Ingersoll-Rand, SSR, Dublin, Ireland), which maintained the relative humidity above $65 \%$ throughout the day. To control the solar radiation, a shade netting was used (Aluminet 30\%, Novedades Agrícolas, Murcia, Spain), and for irrigation, a Hoagland nutrient solution was utilized, composed of $6 \mathrm{mM} \mathrm{KNO}_{3}, 4 \mathrm{mM} \mathrm{Ca}\left(\mathrm{NO}_{3}\right)_{2}$, $2 \mathrm{mM} \mathrm{KH} \mathrm{PO}_{4}, 2 \mathrm{mM} \mathrm{MgSO}, 20 \mu \mathrm{M}$ EDDHA-Fe, $25 \mu \mathrm{M} \mathrm{H}_{3} \mathrm{BO}_{3}, 2 \mu \mathrm{M} \mathrm{MnSO}_{4}, 2 \mu \mathrm{M} \mathrm{ZnSO}_{4}, 0.5 \mu \mathrm{M}$ $\mathrm{CuSO}_{4}, 0.4 \mu \mathrm{M}\left(\mathrm{NH}_{4}\right)_{6} \mathrm{Mo}_{27} \mathrm{O}_{24}$. This nutrient solution was prepared from the commercial fertilizers $\mathrm{KNO}_{3}, \mathrm{CaNO}_{3}$, $\mathrm{KH}_{2} \mathrm{PO}_{4}, \mathrm{MgSO}_{4}$, and a mix of micronutrients. The water used for the preparation of the nutrient solutions came from the Tajo-Segura transfer, and it was deionized with an inverse osmosis system (KP45HWL, CWG, Zagreb, Croatia). The treatments with $\mathrm{NaCl}$ were imposed by watering with a salt concentration of $20 \mathrm{mM} \mathrm{NaCl}$ at first, and this concentration was increased daily in $20 \mathrm{mM}$ increments successively until the desired concentration for each treatment was reached $(\mathrm{mM} \mathrm{NaCl})$ : T0 (0), T1 (40), T2 (60), T3 (80), T4 (100), T5 (120), and T6 (140). Thus, the plants did not suffer any osmotic shock. T0 was the control treatment where no $\mathrm{NaCl}$ was added. These $\mathrm{NaCl}$ concentrations are equivalent to the next electrical conductivity $\left(\mu \mathrm{S} \mathrm{cm}{ }^{-1}\right)$ of $2.4,5.5,8.0,9.6,11.2,12.9$, 14.0 , and the nutrient solution had a $\mathrm{pH}$ of 6.5 in all $\mathrm{NaCl}$ treatment.

A bifactorial experimental design was utilized, consisting of factors cultivar (C), with three cultivars, and factor of salt treatment (S) with seven saline treatments. Each combination cultivar $\times$ salt treatment $(\mathrm{C} \times \mathrm{S})$ used six plants that were randomly placed in the greenhouse. The duration of the experiment was $70 \mathrm{~d}$, and then the corresponding analytical measurements were performed.

Parameters of gas exchange and chlorophyll (Chl) fluorescence: At the end of the experiment, the following gas-exchange parameters were measured: net assimilation of $\mathrm{CO}_{2}\left(P_{\mathrm{N}}\right)$, stomatal conductance $\left(g_{\mathrm{S}}\right)$, leaf transpiration $(E)$, and intercellular $\mathrm{CO}_{2}$ concentration $\left(C_{\mathrm{i}}\right)$. These parameters were measured between 8:00 and 11:00 h using a portable gas analyzer for the measurement of photosynthesis and gas exchange (CIRAS-2, PP-System, Amesbury, Massachusetts, USA). During the measurement phase, the equipment was configured to maintain a constant intensity of light [PAR of $1,000 \mu \mathrm{mol}\left(\right.$ photon) $\mathrm{m}^{-2} \mathrm{~s}^{-1}$ ] and $\mathrm{CO}_{2}$ concentration $(400 \mathrm{ppm})$ in the measuring chamber. 
Chl measurements were performed on the same days and the same leaves used for measuring the gas-exchange parameters, using a modulated pulse portable fluorimeter (FMS-2, Hansatech Instruments, Norfolk, UK). The leaves used were previously conditioned in the dark for $30 \mathrm{~min}$ and illuminated for $5 \mu$ s to induce fluorescence. The initial $\left(\mathrm{F}_{0}\right)$ and maximum $\left(\mathrm{F}_{\mathrm{m}}\right)$ fluorescence were determined, and the variable fluorescence $\left(\mathrm{F}_{\mathrm{v}}=\mathrm{F}_{\mathrm{m}}-\mathrm{F}_{0}\right)$, the $\mathrm{F}_{\mathrm{v}} / \mathrm{F}_{\mathrm{m}}$ ratio, and the $F_{v} / F_{0}$ ratio were calculated. This equipment was also used to calculate the fluorescence kinetics of leaves adapted to light. The parameters measured were: PSII quantum yield, $\Phi_{\text {PSII }}=\left(F_{\mathrm{m}}{ }^{\prime}-F_{0}{ }^{\prime}\right) / F_{m}{ }^{\prime}$; PSII maximum efficiency, $\mathrm{F}_{\mathrm{v}}{ }^{\prime} / \mathrm{F}_{\mathrm{m}}{ }^{\prime}=\left(\mathrm{F}_{\mathrm{m}}{ }^{\prime}-\mathrm{F}_{0}{ }^{\prime}\right) / \mathrm{F}_{\mathrm{m}}{ }^{\prime}$; and photochemical quenching decay, $\mathrm{q}_{\mathrm{P}}=\left(\mathrm{F}_{\mathrm{m}}{ }^{\prime}-\mathrm{F}_{\mathrm{s}}\right) /\left(\mathrm{F}_{\mathrm{m}}{ }^{\prime}-\mathrm{F}_{0}{ }^{\prime}\right)$, where $\mathrm{F}_{\mathrm{s}}$ is the fluorescence performance in a stable state, $F_{m}{ }^{\prime}$ is the maximum value when all the reaction centers are closed after a saturating light pulse $\left[12,000 \mu \mathrm{mol}\left(\right.\right.$ photon) $\mathrm{m}^{-2} \mathrm{~s}^{-1}$ for $0.8 \mathrm{~s}$ ], and $\mathrm{F}_{0}{ }^{\prime}$ is the minimum fluorescence in the state of adaptation to the light obtained by temporarily turning off the actinic light and applying a pulse of far-red light $(735 \mathrm{~nm})$ to drain the PSII of electrons.

Water relations: To understand the water status of the plants, a plant water status study was conducted at the end of the experiment by measuring the midday water potential $\left(\Psi_{\mathrm{w}}\right)$ and relative water content $(\mathrm{RWC})$. The $\Psi_{\mathrm{w}}$ was determined by using a pressure chamber (Model 670, PMS Instrument, Corvallis, Oregon, USA) in completely expanded leaves found in the middle part of the plant (Scholander et al. 1965). The values were recorded as psi (pounds per square inch) and transformed to $\mathrm{MPa}$ with the following equation: $\Psi_{\mathrm{w}}=[-(0.0687 \times \mathrm{psi}+0.091) / 10]$.

The RWC was measured in leaves similar to those used to measure water potential. The leaves were collected at midday (11:00-12:00 h) and were immediately weighed to obtain their fresh mass. The leaves were then placed in scintillation vials with the petioles submerged in deionized water, and were maintained at this state overnight in the dark at $4^{\circ} \mathrm{C}$. Then, the saturated leaves were measured once again and dried at $60^{\circ} \mathrm{C}$ for $48 \mathrm{~h}$ to obtain their dry mass (Morgan 1984). The RWC was calculated as: RWC = [(fresh mass - dry mass $) \times 100 /($ saturated mass - dry mass).

Determination of carbohydrates and chlorides: At the end of the experiment, ten leaves from each plant were taken to determine the carbohydrates and the $\mathrm{Cl}^{-}$contents. The total nonstructural carbohydrate (TNC) content in leaves was determined through extraction with ethanol $(80 \%)$ of the dry plant material. Anthrone method (Hodge and Hofreiter 1962) was used to determine the total soluble sugars (TSS). Reducing sugars (RS) were analysed with the protocol described by Nelson (1944) and Somogyi (1952). The concentration of starch was obtained from the dry pellet, through an extraction with $\operatorname{MES}(0.5 \mathrm{M})$ at $\mathrm{pH} 5$, and measuring it by using the protocol by Haissig and Dickson (1979). The concentration of $\mathrm{Cl}^{-}$was measured with a chlorometer (Corning 926, Sherwood Scientific, Cambridge, England), after a previous extraction with deionized water.
Statistical analysis: The statistical treatment of the data included a basic statistic description (mean values and standard errors of the repetitions for each cultivar $\times$ salt treatment combination), two-way analysis of variance (ANOVA), and Duncan's test for the separation of means for each cultivar, for those parameters where the main factor of salinity was significant $(P<0.05)$ in the ANOVA. Each cultivar $\times$ salt treatment $(\mathrm{C} \times \mathrm{S})$ used six plants. The statistical package used was IBM SPSS Statistics 22 (Armonk, NY). For the creation of the graphics and regression analysis, the software program SigmaPlot 13.0 (Systat Software, San Jose, CA) was utilized.

\section{Results}

Gas exchange: In general, the salinity decreased $P_{\mathrm{N}}, g_{\mathrm{s}}$, and $E$, although their response was dependent on the cultivar. The $P_{\mathrm{N}}$ of the variety 'Mollar' decreased slightly with the increase of salinity in the irrigation water, this decrease became significant at T4 $(100 \mathrm{mM})$ with a reduction of $36 \%$ compared to the control, reaching a reduction of $56 \%$ in treatment T6 (140 mM, Fig. 1). In the case of the variety 'Valenciana', a decrease of $50 \%$ was already observed in the lowest salt treatment (T1, $40 \mathrm{mM})$ with respect to the control. However, the application of higher salinity did not result in a significant variation until T6 $(60 \%)$. On the other hand, in 'Wonderful', the $P_{\mathrm{N}}$ was progressively reduced until $\mathrm{T} 3(80 \mathrm{mM}$, a $43 \%$ reduction $)$, and starting at this point, it decreased more slowly until reaching a final reduction of $61 \%$. The $C_{\mathrm{i}}$ was not affected by the salt treatment in varieties 'Mollar' and 'Wonderful', while in the variety 'Valenciana', only a significant decrease was evidenced starting with the T3 treatment, after which it became stable. In the variety 'Mollar', the $g_{\mathrm{s}}$ significantly decreased in the first treatment, after which, it was maintained statistically stable until T6, where it decreased again. In variety 'Valenciana', T1 significantly decreased $g_{\mathrm{s}}$ for more than $50 \%$ with respect to the control values (T0), without significant differences found in any of the treatments with higher salt concentrations. In variety 'Wonderful', $g_{\text {s }}$ started to decrease from T2 reaching the maximum reduction in T6 treatment, although there were not significant differences between T2, T3, T4, and T5 treatments. The salt treatments induced significant reductions of $E$; in the varieties 'Mollar' and 'Valenciana', the leaf $E$ significantly decreased at the T1 treatment, while in the variety 'Wonderful', the decrease of this parameter was significant starting with the $\mathrm{T} 5$ concentration (120 mM).

The $P_{\mathrm{N}}$ showed a significant polynomic relationship with $g_{\mathrm{s}}$, as the $g_{\mathrm{s}}$ increased, the $P_{\mathrm{N}}$ was enhanced, with a linear section observed in the $g_{\mathrm{s}}$ range between 20-60 mol $\mathrm{m}^{-2} \mathrm{~s}^{-1}$ (Fig. 2A). However, the $P_{\mathrm{N}}$ had a good linear correlation with the quantum yield of PSII ( $\Phi_{\text {PSII }}$, Fig. $2 C$ ), but the correlations with the leaf chlorine concentration were very weak (Fig. $2 D$ ). $P_{\mathrm{N}}$ showed a good correlation with $C_{\mathrm{i}}$ (Fig. $2 B$ ), although the regression model depended on pomegranate variety. Thus, 'Mollar' and 'Valenciana' varieties fitted to a linear regression, while 'Wonderful' fitted to a quadratic regression. 


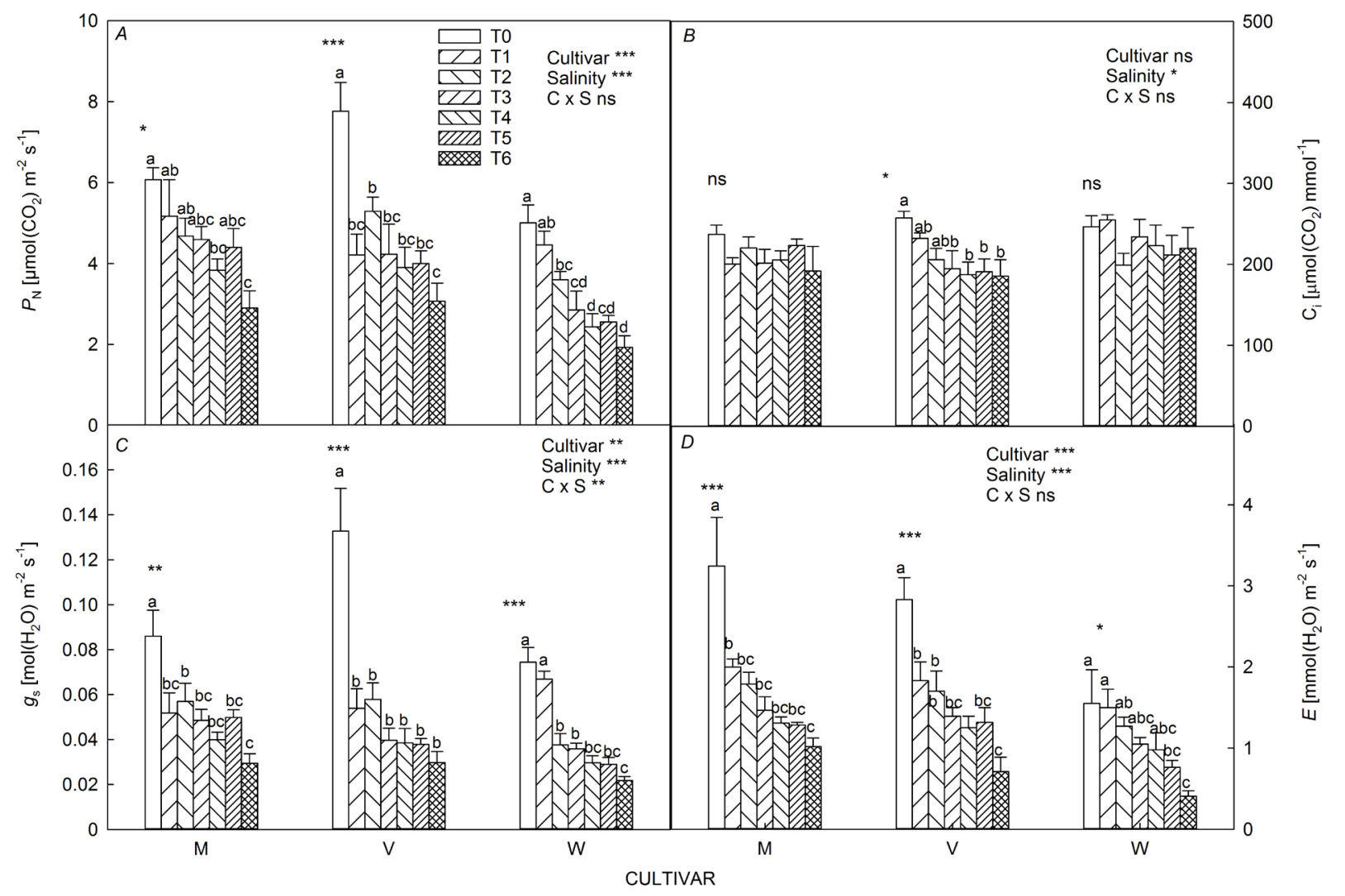

Fig. 1. Parameters of gas exchange. Net assimilation of $\mathrm{CO}_{2}\left(P_{\mathrm{N}}\right)(A)$, intercellular $\mathrm{CO}_{2}\left(C_{\mathrm{i}}\right)(B)$, stomatal conductance $\left(g_{\mathrm{s}}\right)(C)$, and leaf transpiration $(E)(D)$ in three different cultivars of pomegranate: 'Mollar' (M), 'Valenciana' (V), and 'Wonderful' (W), watered with seven salt treatments: $0 \mathrm{mM}$ (control, T0), $40 \mathrm{mM}$ (T1), $60 \mathrm{mM}$ (T2), $80 \mathrm{mM}$ (T3), $100 \mathrm{mM}$ (T4), $120 \mathrm{mM}$ (T5), and 140 mM (T6) NaCl for $70 \mathrm{~d}$. The vertical bars represent the standard error of the mean $(n=6)$. The lowercase letters indicate significant differences between the salt treatments at $P<0.05$ established by Duncan's multiple range test. In the ANOVA, ns indicates insignificant differences at $95 \%$. ${ }^{*},{ }^{* *}$, and ${ }^{* * *}$ indicate significant differences at $P<0.05,0.01$, and 0.001 , respectively.

Chl fluorescence parameters: According to the ANOVA for the Chl fluorescence parameters (Fig. 3), it could be observed that the four parameters studied, quantum yield of PSII $\left(\Phi_{\text {PSII }}\right)$, photochemical quenching coefficient $\left(q_{p}\right)$, performance of PSII antenna $\left(\mathrm{F}_{\mathrm{v}}{ }^{\prime} / \mathrm{F}_{\mathrm{m}}{ }^{\prime}\right)$, and variable fluorescence/maximum fluorescence ratio $\left(\mathrm{F}_{\mathrm{v}} / \mathrm{F}_{\mathrm{m}}\right)$, were strongly influenced by the cultivar as well as by salinity. There was also a highly significant interaction in $\mathrm{F}_{\mathrm{v}} / \mathrm{F}_{\mathrm{m}}$, and a moderately significant one in the $\mathrm{F}_{\mathrm{v}}{ }^{\prime} / \mathrm{F}_{\mathrm{m}}$ ' ratio.

The varieties 'Mollar' and 'Wonderful' showed a progressive and significant decrease in $\Phi_{\text {PSII }}$ as the concentration of $\mathrm{NaCl}$ increased in the nutrient solution, as opposed to the behavior of 'Valenciana', where the decrease was less pronounced, and there was hardly a significant difference between the treatments (Fig 3A). For the $\mathrm{q}_{\mathrm{P}}$, in the variety 'Mollar', the behavior was irregular with respect to salinity (Fig. 3B), with a significant decrease with the application of T3 $(80 \mathrm{mM})$, a posterior increase until reaching statistically equal values to the control when reaching treatment T5 $(120 \mathrm{mM})$, to the later decrease with treatment T6 $(140 \mathrm{mM})$. The variety 'Valenciana', on the other hand, did not show significant differences in this parameter in the different salt treatments. However, the variety 'Wonderful' showed a trend similar to the decrease of $\Phi_{\mathrm{PSII}}$. In the variety 'Mollar', $\mathrm{F}_{\mathrm{v}}{ }^{\prime} / \mathrm{F}_{\mathrm{m}}$ ' decreased significantly when the salinity reached the T3 values, being maintained for treatments $\mathrm{T} 4, \mathrm{~T} 5$, and $\mathrm{T} 6$ (Fig. 3C). Similarly, in the variety 'Valenciana', $\mathrm{F}_{\mathrm{v}}{ }^{\prime} / \mathrm{F}_{\mathrm{m}}$ ' was significantly reduced with $\mathrm{T} 3$, and then remained stable in the latter treatments with higher concentrations of salt. In the variety 'Wonderful', the behavior was similar as the one seen for the quantum yield of PSII. $\mathrm{F}_{\mathrm{v}}{ }^{\prime} / \mathrm{F}_{\mathrm{m}}$ ' progressively decreased with increasing $\mathrm{NaCl}$ concentration in the nutrient solution, with significant decrease under T3, T4, and T5. For the response of $\mathrm{F}_{\mathrm{v}} / \mathrm{F}_{\mathrm{m}}$, it was observed in the variety 'Mollar', that the values of the $F_{v} / F_{m}$ ratio significantly decreased with the application of $\mathrm{T} 3$, becoming stable when the concentration increased (Fig. 3D). However, the variety 'Valenciana' showed an irregular behavior after the application of different salt concentrations, showing a significant decrease with the application of T4, but obtaining similar values for T3 and T6. The variety 'Wonderful' showed a more regular behavior, with the $\mathrm{F}_{\mathrm{v}} / \mathrm{F}_{\mathrm{m}}$ values decreasing with increasing $\mathrm{NaCl}$ concentration in the nutrient solution, with significant decreases found in $\mathrm{T} 4$ and $\mathrm{T} 5$.

Concentration of chloride in leaves: The three varieties showed a similar behavior in their concentration of $\mathrm{Cl}^{-}$in leaves with respect to the salt treatments (Fig. 4). 

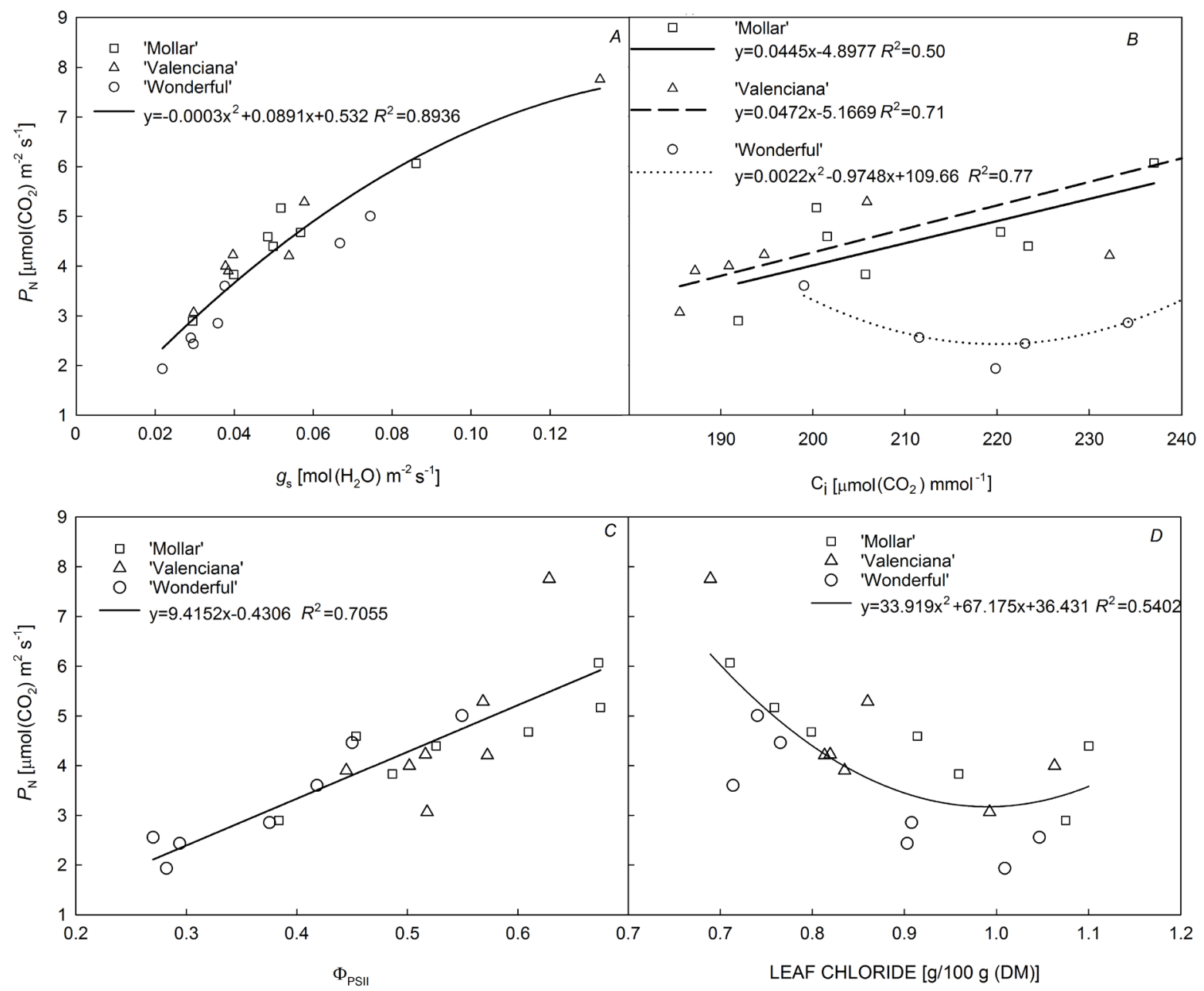

Fig. 2. Regressions of the net assimilation of $\mathrm{CO}_{2}\left(P_{\mathrm{N}}\right)$ with stomatal conductance $\left(g_{\mathrm{s}}\right)(A)$, intercellular $\mathrm{CO}_{2}$ concentration $\left(C_{\mathrm{i}}\right)(B)$, quantum efficiency of PSII ( $\left.\Phi_{\text {PSII }}\right)(C)$, and leaf chloride concentration $(D)$.

The concentration showed a regular increase when the concentration of $\mathrm{NaCl}$ increased in the nutrient solution, reaching the highest values in T5 $(120 \mathrm{mM})$, with these being similar to those found in T6 $(140 \mathrm{mM})$.

Water relations: The water potential at midday $\left(\Psi_{\mathrm{w}}\right)$ decreased as the concentration of $\mathrm{NaCl}$ increased in the nutrient solution, and this behavior was similar in all the cultivars according to the ANOVA (no interaction was found between salinity and cultivar). The $\Psi_{\mathrm{w}}$ of the variety 'Mollar' (Fig. 5) showed significant decrease with the application of treatments T1, T3, T4, and T6. In the variety 'Valenciana', there were significant changes with the application of T1, T5, and T6, but reached lower values with respect to 'Mollar' and 'Wonderful'. In this last variety, the tendency followed a stepwise pattern, with significant changes occurring for T1, T3, and T5 treatments. Regarding the relative water content, no significant differences were found between treatments for any of the cultivars studied.

Concentration of carbohydrates: Table 1 shows the results of the leaf carbohydrate concentrations and their
ANOVA. For the variety 'Mollar', the TSS showed a general tendency to decrease as the concentration of salt increased in the irrigation water. This decrease ranged from $86.9-78.1 \mathrm{mg} \mathrm{g}^{-1}(\mathrm{DM})$ from control to $\mathrm{T} 6$ treatment. Although a significant increase of these sugars was observed in treatments $\mathrm{T} 4(100 \mathrm{mM})$ and T5 $(120 \mathrm{mM})$ relative to the control, before decreasing again to values of $78.1 \mathrm{mg} \mathrm{g}^{-1}(\mathrm{DM})$. In the case of starch, the concentrations of $17.4 \mathrm{mg} \mathrm{g}^{-1}(\mathrm{DM})$ obtained initially tended to increase until the application of T3 $(80 \mathrm{mM})$, and then decreased to values that were statistically similar to the initial ones. The RS tended to increase progressively from the initial values of $30.6 \mathrm{mg} \mathrm{g}^{-1}(\mathrm{DM})$, reaching a maximum value of $61.6 \mathrm{mg} \mathrm{g}^{-1}(\mathrm{DM})$ with $\mathrm{NaCl}$ concentration of $100 \mathrm{mM}$, after which it was reduced to $56.9 \mathrm{mg} \mathrm{g}^{-1}(\mathrm{DM})$. For the TSS:RS ratio, the values decreased from an initial value of 2.91 to 1.45 , which suggests a response of this variety to salinity resulting in the storage of reducing sugars as opposed to soluble ones.

In the case of the variety 'Valenciana', the soluble sugars, as well as the starch, showed a general tendency to increase, shifting from initial values of 68.6 and $17.6 \mathrm{mg} \mathrm{g}^{-1}(\mathrm{DM})$, respectively, to final values of 107.0 


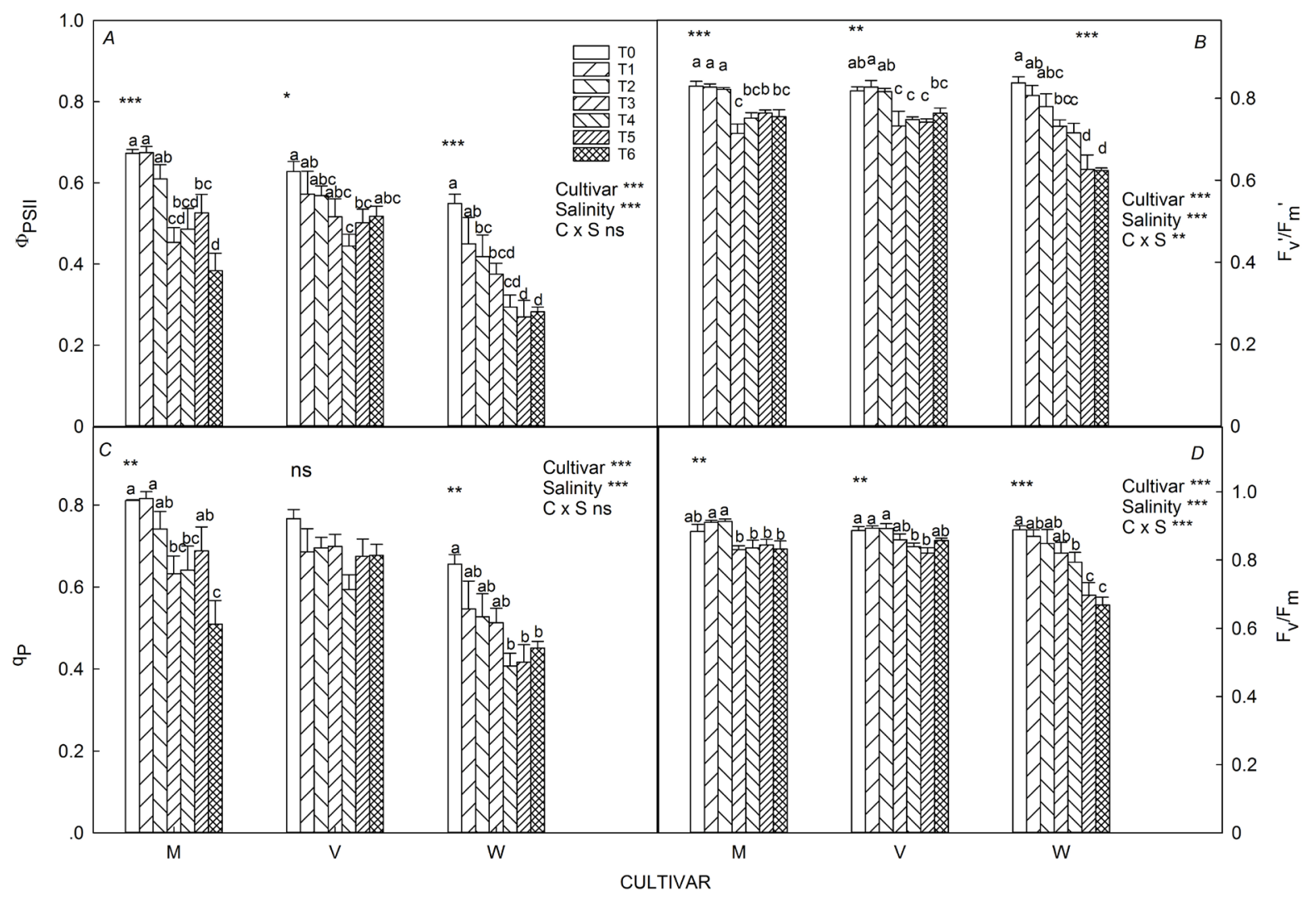

Fig. 3. Chlorophyll fluorescence. Quantum efficiency of PSII $\left(\Phi_{\text {PSII }}\right)(A)$, performance of the PSII antenna $\left(\mathrm{F}_{\mathrm{v}}{ }^{\prime} / \mathrm{F}_{\mathrm{m}}{ }^{\prime}\right)(B)$, photochemical coefficient $\left(\mathrm{q}_{\mathrm{p}}\right)(C)$, and variable fluorescence/maximum fluorescence ratio $\left(\mathrm{F}_{\mathrm{v}} / \mathrm{F}_{\mathrm{m}}\right)(D)$ in three cultivars of pomegranate: 'Mollar' $(\mathrm{M})$, 'Valenciana' (V), and 'Wonderful' (W); watered with seven salt treatments: $0 \mathrm{mM}$ (control, T0), $40 \mathrm{mM}$ (T1), $60 \mathrm{mM}$ (T2), $80 \mathrm{mM}$ (T3), $100 \mathrm{mM}$ (T4), $120 \mathrm{mM}$ (T5), and $140 \mathrm{mM}$ (T6) NaCl for $70 \mathrm{~d}$. The vertical bars represent the standard error of the mean $(n=6)$. The lowercase letters indicate significant differences between the salt treatments at $P<0.05$ established by Duncan's multiple range test.

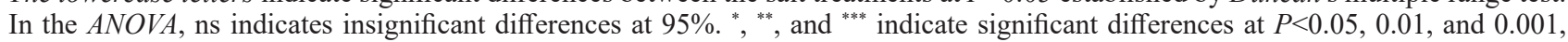
respectively.

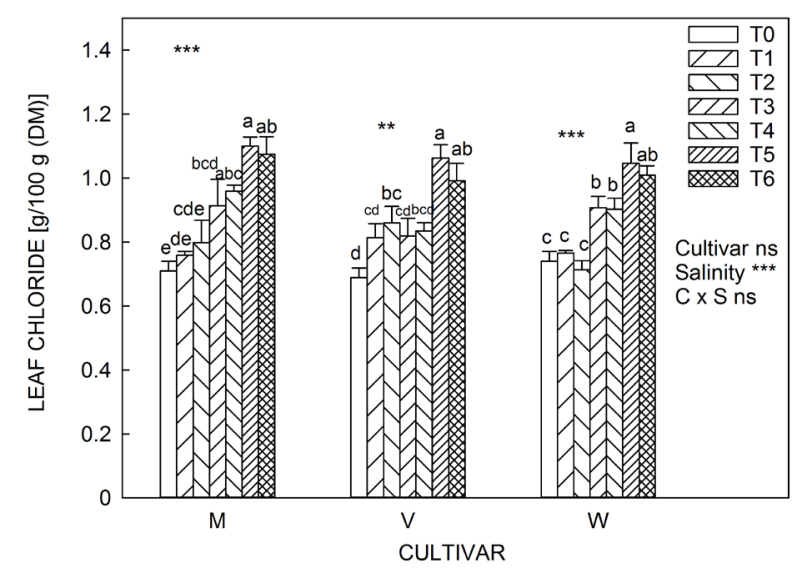

Fig. 4. Leaf chloride concentration in three cultivars of pomegranate: 'Mollar' (M), 'Valenciana' (V), and 'Wonderful' (W), watered with seven salt treatments: $0 \mathrm{mM}$ (control, T0), $40 \mathrm{mM}$ (T1), $60 \mathrm{mM}$ (T2), $80 \mathrm{mM}$ (T3), $100 \mathrm{mM}$ (T4), $120 \mathrm{mM}$ (T5), and $140 \mathrm{mM}(\mathrm{T} 6) \mathrm{NaCl}$ for $70 \mathrm{~d}$. The vertical bars represent the standard error of the mean $(n=6)$. The lowercase letters indicate significant differences between the salt treatments at $P<0.05$ established by Duncan's multiple range test. In the ANOVA, ns indicates insignificant differences at $95 \%$. $^{*},{ }^{* *}$, and ${ }^{* * *}$ indicate significant differences at $P<0.05,0.01$, and 0.001 , respectively. and $23.5 \mathrm{mg} \mathrm{g}^{-1}(\mathrm{DM})$, respectively. The $\mathrm{RS}$ values were generally found to be stable, with a single increase in T5, while the TSS:RS ratio showed an irregular tendency, with decreases alternating with significant increases under increasing salinity.

In the variety 'Wonderful', the TSS initially increased from control values of 29.4 to $61.5 \mathrm{mg} \mathrm{g}^{-1}$ (DM) (T2), and from here the concentration was maintained statistically stable. However, the starch in the leaves showed another pattern. Under control conditions, the starch concentration was $20.9 \mathrm{mg} \mathrm{g}^{-1}(\mathrm{DM})$, and the salt treatments $\mathrm{T} 1$, T5, and T6 decreased it, reaching the lowest value in T5. On the other hand, the salt treatments $\mathrm{T} 2, \mathrm{~T} 3$, and $\mathrm{T} 4$ did not alter the leaf starch concentration relative to the control treatment. The RS concentration was generally maintained constant, with a slight increase towards the final salt concentrations (T5 and T6). Given that the RS did not vary in an important manner as compared to the TSS, the TSS:RS ratio increased significantly, from 0.91 in the control treatment to 2.21 in the treatment with $80 \mathrm{mM}$ of $\mathrm{NaCl}$ (T3). However, this value significantly decreased to 1.46 (T5) and 1.20 (T6), coinciding with the increase of the RS in the last treatments. 


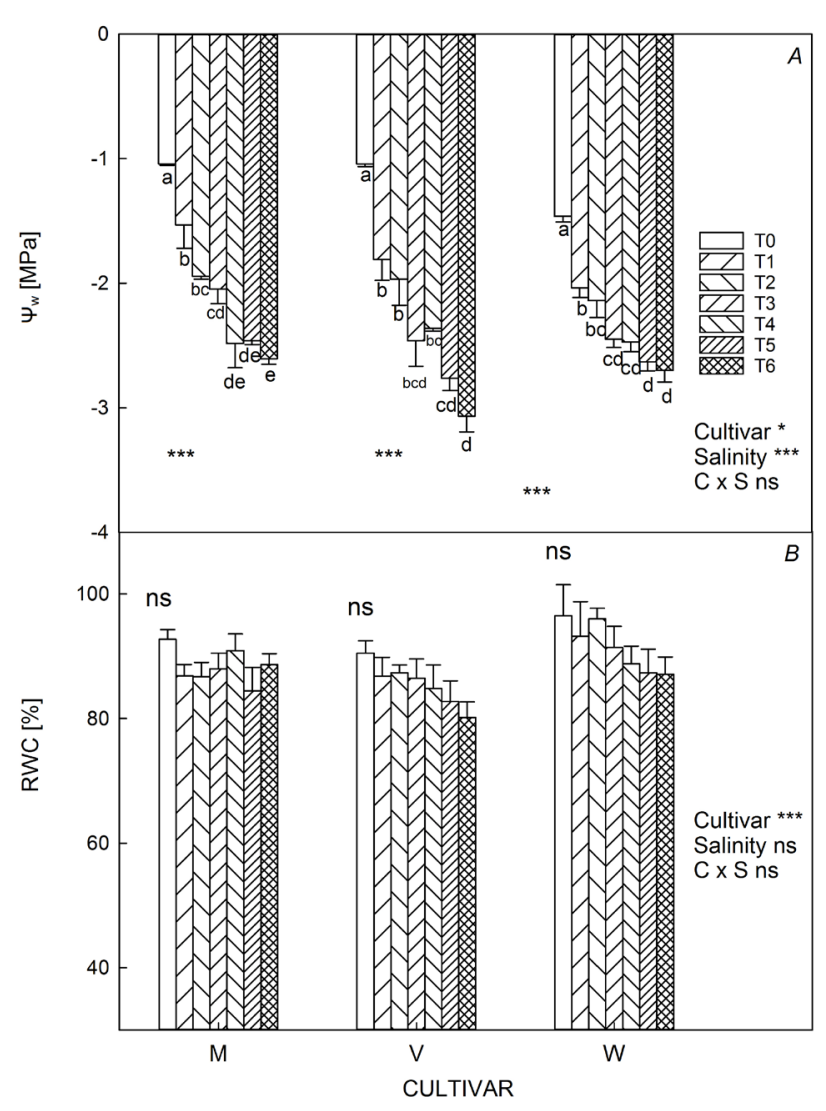

Fig. 5. Water potential at midday $\left(\Psi_{\mathrm{w}}\right)(A)$ and relative water content $(\mathrm{RWC})(B)$ in three cultivars of pomegranate: 'Mollar' $(\mathrm{M})$, 'Valenciana' (V), and 'Wonderful' (W), watered with seven salt treatments: $0 \mathrm{mM}$ (control, T0), $40 \mathrm{mM}$ (T1), $60 \mathrm{mM}$ (T2), $80 \mathrm{mM}$ (T3), $100 \mathrm{mM}$ (T4), $120 \mathrm{mM}$ (T5), and $140 \mathrm{mM}$ (T6) NaCl for $70 \mathrm{~d}$. The vertical bars represent the standard error of the mean $(n=6)$. The lowercase letters indicate significant differences between the salt treatments at $P<0.05$ established by Duncan's multiple range test. In the $A N O V A$, ns indicates insignificant differences at $95 \%$. ${ }^{*},{ }^{* *}$, and ${ }^{* * *}$ indicate significant differences at $P<0.05,0.01$, and 0.001 , respectively.

\section{Discussion}

In this work, we observed that salinity in the irrigation water altered the physiological processes of pomegranate plants related to gas-exchange processes, Chl fluorescence, water relations, and carbon metabolism, as reported by the decrease of the variables net $\mathrm{CO}_{2}$ assimilation, stomatal conductance, $\mathrm{F}_{\mathrm{v}} / \mathrm{F}_{\mathrm{m}}$ ratio, quantum yield of PSII, TSS, and TSS:RS ratio. The net assimilation of $\mathrm{CO}_{2}$ results (Fig. 1) showed no significant interaction between $\mathrm{C} \times \mathrm{S}$, which means that the response of these three varieties was similar, with a decrease of $P_{\mathrm{N}}$ observed with increasing $\mathrm{NaCl}$ concentration in the nutrient solution. It should be highlighted that in the variety 'Valenciana', the $P_{\mathrm{N}}$ was significantly reduced starting from $\mathrm{T} 1(40 \mathrm{mM} \mathrm{NaCl})$, while in the varieties 'Mollar' and 'Wonderful', $P_{\mathrm{N}}$ was reduced starting at $\mathrm{T} 4(100 \mathrm{mM} \mathrm{NaCl})$ and $\mathrm{T} 2(60 \mathrm{mM})$, respectively. Also, the salt treatments which produced a reduction of $P_{\mathrm{N}}$ equal or higher than $50 \%$, relative to the control treatment, was T6 for 'Mollar', T1 for 'Valenciana', and T4 for 'Wonderful'. This suggests that the photosynthetic apparatus of the variety 'Valenciana' was either more sensitive to salinity than that of the other two, or this variety has a series of physiological mechanisms for palliating the negative effects of salinity, which were different from the other two varieties. On the other hand, the causes responsible for the decrease of $P_{\mathrm{N}}$ were different for each cultivar. The effect of salinity on the $P_{\mathrm{N}}$ in many species of plants occurs due to two factors: stomatal and/ or nonstomatal. The stomatal factor refers to the closing of stomata which causes a reduction in the partial pressure of $\mathrm{CO}_{2}$ in the mesophyll cells of the leaves, while the nonstomatal factor refers to the damages caused to the metabolic processes of $\mathrm{CO}_{2}$ fixation (Lawlor and Cornic 2002, Meloni et al. 2003, DeRidder and Salvucci 2007). The parameter of intercellular concentration $\left(C_{\mathrm{i}}\right.$; Farquhar and Sharkey 1982) provides us with information which of the two factors was responsible for the loss of $P_{\mathrm{N}}$. In our experiment, it could be observed that salinity decreased $C_{\mathrm{i}}$ in the variety 'Valenciana', which implied that the decrease of $P_{\mathrm{N}}$ was due to the stomata closure. However, in the other two varieties ('Mollar' and 'Wonderful'), the $P_{\mathrm{N}}$ decreased due to metabolic damage, as shown by $C_{\mathrm{i}}$, which did not change with salinity. Aside from the $C_{\mathrm{i}}$ values, the parameters obtained by the Chl fluorescence study support the hypothesis that the nonstomatal factors were important in the reduction of the $P_{\mathrm{N}}$ in the varieties 'Wonderful' and 'Mollar', as in these plants, an important reduction of quantum yield of PSII $\left(\Phi_{\text {PSII }}\right)$ was observed (a reduction of 48 and $41 \%$, respectively), and this was due to the reduction of $\mathrm{F}_{\mathrm{v}}{ }^{1} / \mathrm{F}_{\mathrm{m}}{ }^{\prime}$ and $\mathrm{q}_{\mathrm{P}}$ as well. The decrease of these factors means that these plants lowered efficiency of converting light energy to chemical energy (Maxwell and Johnson 2000) due to the damage in processes of capture and transport of light energy from the photosynthetic pigments to the reaction center of PSII $\left(\mathrm{F}_{\mathrm{v}}{ }^{\prime} / \mathrm{F}_{\mathrm{m}}{ }^{\prime}\right)$, as well as the metabolic processes related to the Calvin cycle $\left(\mathrm{q}_{\mathrm{P}}\right)$. In the regression study of the parameters of gas exchange as compared to the parameters of $\mathrm{Chl}$ fluorescence, this idea can be clearly observed, where the decrease of the $P_{\mathrm{N}}$ is accompanied with a decrease of $\Phi_{\text {PSII }}$ (Fig. 2C), $F_{\mathrm{v}}{ }^{\prime} / \mathrm{F}_{\mathrm{m}}{ }^{\prime}$, and $\mathrm{q}_{\mathrm{P}}$ (data not shown).

The reduction and/or inhibition of the plant's growth, when exposed to salt $(\mathrm{NaCl})$ in the nutrient solution, can be attributed to drastic changes of the water status of plants (osmotic effect of salinity), toxicity due to the excessive accumulation of $\mathrm{Cl}^{-}$and $\mathrm{Na}^{+}$in the different plant tissues, and the nutritional disequilibrium caused by alterations in the absorption of essential nutrients (Munns 2002, Rodrigues 2007). The study conducted in our assay of water and mineral nutrition (analysis of $\mathrm{Cl}^{-}$in leaves), showed that, when the concentration of $\mathrm{NaCl}$ increased in the nutrient solution, the concentration of $\mathrm{Cl}^{-}$increased in the leaves, while the water potential decreased. This behavior was similar in all three varieties, as a significant interaction between $\mathrm{C} \times \mathrm{S}$ in the ANOVA was not found. Despite the fact that the water potential decreased with salinity, the RWC was not affected significantly. This result allowed us to discard the osmotic effect of the salinity as 
Table 1. Total soluble sugars (TSS), starch, reducing sugars (RS), and total soluble sugars:reducing sugars ratio (TSS:RS) in three different cultivars of pomegranate: 'Mollar', 'Valenciana', and 'Wonderful', watered with seven salt treatments: 0 mM (control, T0), $40 \mathrm{mM}$ (T1), $60 \mathrm{mM}$ (T2), $80 \mathrm{mM}$ (T3), $100 \mathrm{mM}$ (T4), $120 \mathrm{mM}$ (T5), and $140 \mathrm{mM}$ (T6) NaCl for $70 \mathrm{~d}$. In the ANOVA, ** and *** indicate significant differences at $P<0.01$ and $P<0.001$, respectively. The lowercase letters indicate significant differences between the salt treatments at $P<0.05$ established by Duncan's multiple range test. The values are means $\pm \operatorname{SE}(n=6)$.

\begin{tabular}{|c|c|c|c|c|c|}
\hline Cultivar & Treatment & $\mathrm{TSS}\left[\mathrm{mg} \mathrm{g}^{-1}(\mathrm{DM})\right]$ & Starch $\left[\mathrm{mg} \mathrm{g}^{-1}(\mathrm{DM})\right]$ & $\mathrm{RS}\left[\mathrm{mg} \mathrm{g}^{-1}(\mathrm{DM})\right]$ & TSS:RS \\
\hline \multirow[t]{7}{*}{ 'Mollar' } & $\mathrm{T} 0$ & $86.9 \pm 0.49^{\mathrm{a}}$ & $17.4 \pm 0.49^{c}$ & $30.6 \pm 2.50^{c}$ & $2.91 \pm 0.23^{\mathrm{a}}$ \\
\hline & $\mathrm{T} 1$ & $72.7 \pm 3.11^{\mathrm{b}}$ & $21.9 \pm 0.43^{b}$ & $51.3 \pm 2.24^{\mathrm{ab}}$ & $1.41 \pm 0.04^{c}$ \\
\hline & $\mathrm{T} 2$ & $73.7 \pm 1.20^{\mathrm{b}}$ & $25.1 \pm 0.37^{\mathrm{a}}$ & $50.9 \pm 2.02^{\mathrm{ab}}$ & $1.46 \pm 0.07^{\mathrm{c}}$ \\
\hline & $\mathrm{T} 3$ & $79.1 \pm 2.88^{b}$ & $24.6 \pm 0.33^{\mathrm{a}}$ & $60.9 \pm 1.32^{\mathrm{a}}$ & $1.30 \pm 0.05^{\mathrm{c}}$ \\
\hline & $\mathrm{T} 4$ & $93.7 \pm 1.63^{\mathrm{a}}$ & $20.3 \pm 0.59^{\mathrm{b}}$ & $61.6 \pm 2.01^{\mathrm{a}}$ & $1.53 \pm 0.07^{\mathrm{c}}$ \\
\hline & $\mathrm{T} 5$ & $93.3 \pm 1.64^{\mathrm{a}}$ & $20.9 \pm 0.40^{\mathrm{b}}$ & $46.3 \pm 4.62^{b}$ & $2.12 \pm 0.26^{b}$ \\
\hline & T6 & $78.1 \pm 2.75^{\mathrm{b}}$ & $18.2 \pm 0.81^{\mathrm{c}}$ & $56.9 \pm 7.06^{\mathrm{ab}}$ & $1.45 \pm 0.16^{\mathrm{c}}$ \\
\hline ANOVA & & $* * *$ & $* * *$ & $* *$ & $* * *$ \\
\hline \multirow[t]{7}{*}{ 'Valenciana' } & $\mathrm{T} 0$ & $68.6 \pm 3.58^{c}$ & $17.6 \pm 0.39^{b}$ & $26.4 \pm 1.00^{c}$ & $2.59 \pm 0.06^{\mathrm{a}}$ \\
\hline & $\mathrm{T} 1$ & $70.8 \pm 2.71^{\mathrm{c}}$ & $17.6 \pm 0.26^{\mathrm{b}}$ & $53.8 \pm 1.64^{b}$ & $1.32 \pm 0.07^{\mathrm{c}}$ \\
\hline & $\mathrm{T} 2$ & $88.8 \pm 3.54^{\mathrm{b}}$ & $22.7 \pm 0.85^{\mathrm{a}}$ & $42.8 \pm 5.64^{\mathrm{b}}$ & $2.18 \pm 0.22^{\mathrm{ab}}$ \\
\hline & $\mathrm{T} 3$ & $85.0 \pm 2.02^{b}$ & $22.8 \pm 0.63^{a}$ & $43.2 \pm 0.60^{\mathrm{b}}$ & $1.96 \pm 0.06^{\mathrm{b}}$ \\
\hline & $\mathrm{T} 4$ & $93.2 \pm 4.93^{b}$ & $19.4 \pm 0.57^{\mathrm{b}}$ & $43.4 \pm 2.25^{\mathrm{b}}$ & $2.14 \pm 0.04^{\mathrm{ab}}$ \\
\hline & $\mathrm{T} 5$ & $94.0 \pm 3.59^{\mathrm{b}}$ & $22.3 \pm 0.56^{\mathrm{a}}$ & $65.5 \pm 3.44^{\mathrm{a}}$ & $1.45 \pm 0.11^{\mathrm{c}}$ \\
\hline & T6 & $107.4 \pm 4.44^{\mathrm{a}}$ & $23.5 \pm 0.54^{\mathrm{a}}$ & $48.3 \pm 3.49^{b}$ & $2.27 \pm 0.20^{\mathrm{ab}}$ \\
\hline ANOVA & & $* * *$ & $* * *$ & $* * *$ & $* * *$ \\
\hline \multirow[t]{7}{*}{ 'Wonderful' } & T0 & $29.4 \pm 2.05^{\mathrm{c}}$ & $20.9 \pm 0.39^{\mathrm{a}}$ & $32.5 \pm 2.44^{\mathrm{bc}}$ & $0.91 \pm 0.06^{\mathrm{c}}$ \\
\hline & $\mathrm{T} 1$ & $34.8 \pm 4.19^{c}$ & $18.6 \pm 0.80^{\mathrm{bc}}$ & $31.5 \pm 1.89^{\mathrm{bc}}$ & $1.10 \pm 0.12^{\mathrm{bc}}$ \\
\hline & $\mathrm{T} 2$ & $61.5 \pm 3.46^{\mathrm{ab}}$ & $20.0 \pm 0.77^{\mathrm{ab}}$ & $39.5 \pm 3.92^{b}$ & $1.64 \pm 0.22^{\mathrm{ab}}$ \\
\hline & $\mathrm{T} 3$ & $57.6 \pm 4.23^{\mathrm{ab}}$ & $20.7 \pm 0.68^{\mathrm{ab}}$ & $26.8 \pm 2.12^{c}$ & $2.21 \pm 0.27^{\mathrm{a}}$ \\
\hline & $\mathrm{T} 4$ & $54.1 \pm 1.39^{\mathrm{ab}}$ & $19.6 \pm 0.60^{\mathrm{abc}}$ & $36.9 \pm 2.80^{\mathrm{bc}}$ & $1.50 \pm 0.12^{\mathrm{bc}}$ \\
\hline & $\mathrm{T} 5$ & $50.9 \pm 1.83^{b}$ & $13.8 \pm 0.47^{\mathrm{d}}$ & $36.6 \pm 4.58^{\mathrm{bc}}$ & $1.46 \pm 0.15^{\mathrm{bc}}$ \\
\hline & T6 & $63.8 \pm 3.06^{\mathrm{a}}$ & $17.6 \pm 0.25^{\mathrm{c}}$ & $53.2 \pm 3.08^{\mathrm{a}}$ & $1.20 \pm 0.04^{\mathrm{bc}}$ \\
\hline ANOVA & & $* * *$ & $* * *$ & $* *$ & $* *$ \\
\hline Cultivar & & $* * *$ & $* * *$ & $* * *$ & $* * *$ \\
\hline Salinity & & $* * *$ & $* * *$ & $* * *$ & $* * *$ \\
\hline $\mathrm{C} \times \mathrm{S}$ & & $* * *$ & $* * *$ & $* * *$ & $* * *$ \\
\hline
\end{tabular}

being responsible for the reduction of the $P_{\mathrm{N}}$. All the data point out that the decrease of the $P_{\mathrm{N}}$ was due to the toxicity of $\mathrm{Cl}^{-}$in the 'Mollar' and 'Wonderful' varieties, and the stomatal closure in 'Valenciana'. Another result from this study was the finding that the concentration of $\mathrm{Cl}^{-}$in the leaves was relatively low for the high concentrations of $\mathrm{NaCl}$ in the irrigation water, when compared with other crops such as citrus (Syvertsen and Garcia-Sanchez 2014). Mastrogiannidou et al. (2016) and Karimi and Hasanpour (2014) proposed that the pomegranate tree could employ mechanisms of restriction against the transport of $\mathrm{Cl}^{-}$from the root to the shoot of the trees, which allows them to resist the high salinity in the irrigation water. Also, it has been shown that this crop is very resistant against drought (Pourghayoumi et al. 2017). Taking into account that the tolerance of the plants to drought and $\mathrm{Cl}^{-}$toxicity depends on water-use efficiency, among other factors, we could suggest that the pomegranate plants could be resistant to these stresses due to the control they have over leaf transpiration, although this hypothesis has yet to be proven.

Although in most plant species salinity causes altera- tions in the process of $\mathrm{CO}_{2}$ fixation, a single model that estimates how this stress influences the concentration, composition, and distribution of carbohydrates in plants is not available. In various plant species, such as olive trees, salinity induces an increase of the TNC in the leaves, with these carbohydrates intervening in the process of osmotic adjustment that are necessary for maintaining the cellular turgor in the leaves under conditions of low water potential in soil (Tattini et al. 2009). In other species of plants, such as citrus, in which the process of osmotic potential fundamentally depends on the accumulation of $\mathrm{Cl}^{-}$and $\mathrm{Na}^{+}$, the leaf concentrations of carbohydrates decrease due to the decrease of the $P_{\mathrm{N}}$ (Arbona et al. 2005). The increase in the concentration of carbohydrates could be one of the mechanisms employed by plants to resist problems resulting from salinity, through an osmotic adjustment and/or through combating oxidative stress. In our experiment, the concentration of the TSS in the leaves of varieties 'Valenciana' and 'Wonderful' increased with salinity, while the variety 'Mollar' was hardly affected. Also, in the variety 'Mollar' and 'Valenciana', the concentration of the 
RS increased. This implies that in the variety 'Valenciana', the carbon metabolism could have been adjusted so that the carbohydrates intervened in the processes of osmotic adjustment as well as in the deactivation of free radicals of oxygen, while in the varieties 'Wonderful' and 'Mollar', it tends to be directed towards the osmotic adjustment of the plant, or the protection against oxidative stress, respectively. This response was completely different to the one found for the varieties of Iranian pomegranates 'Malas Torsh', 'Malas Shirin', 'Alak Torsh', 'Malas-e-Saveh', and 'Shishe-Kab', where a decrease in the concentration of TSS in the leaves was observed in trees watered with saline water (Naeini et al. 2006, Khayyat et al. 2014).

Conclusion: In this experiment, we described the ecophysiological responses of three pomegranate varieties ('Mollar', 'Valenciana', and 'Wonderful'), using the measurement of parameters of gas exchange, chlorophyll fluorescence, water relations, and the leaf concentration of carbohydrates and $\mathrm{Cl}^{-}$. Although the pomegranate trees are very resistant to salinity, as shown by studies by Maas and Hoffman (1977) and Steppuhn et al. (2005), in our experiment, a different behavior was found in the studied varieties. The variety 'Valenciana' showed a reduction in the $P_{\mathrm{N}}$ due to stomatal closure, while the varieties 'Mollar' and 'Wonderful' could reduce $P_{\mathrm{N}}$ due to damages to their photosynthetic apparatus caused by $\mathrm{Cl}^{-}$toxicity. Also, in the variety 'Valenciana', the carbon metabolism under stress conditions was presumably directed towards the plant osmotic adjustment, as well as towards the reduction of reactive oxygen species. Future research studies should be focused on elucidating the role of antioxidant systems of pomegranate trees in the response to salinity, as it is well known that these plants have fruits and leaves with a great antioxidant capacity.

\section{References}

Arbona V., Marco A., Iglesias D. et al:: Carbohydrate depletion in roots and leaves of salt-stressed potted Citrus clementina L. - Plant Growth Regul. 46: 153-160, 2005.

Ashraf M., Harris P.J.C.: Photosynthesis under stressful environments: An overview. - Photosynthetica 51: 163-190, 2013.

DeRidder B.P., Salvucci M.E.: Modulation of Rubisco activase gene expression during heat stress in cotton (Gossypium hirsutum L.) involves post-transcriptional mechanisms. Plant Sci. 172: 246-254, 2007.

Farquhar G.D., Sharkey T.D: Stomatal conductance and photosynthesis. - Ann. Rev. Plant Physio. 33: 317-345, 1982.

Haissig B.E., Dickson R.E.: Starch measurements in plant tissue using enzymatic hydrolysis. - Physiol. Plantarum 47: 151$157,1979$.

Hodge J.E., Hofreiter B.T.: Determination of reducing sugars and carbohydrates. - In: Whistler R.L., Wolfrom M.L. (ed.): Methods in Carbohydrate Chemistry. Pp. 380-394. Academic Press, New York 1962.

Karimi H.R., Hasanpour Z.: Effects of salinity and water stress on growth and macro nutrients concentration of pomegranate (Punica granatum L.). - J. Plant Nutr. 37: 1937-1951, 2014.

Khayyat M., Tehranifar A., Davarynejad G.H., Sayyari-Zahan M.H.: Vegetative growth, compatible solute accumulation, ion partitioning and chlorophyll fluorescence of 'Malas-e-Saveh' and 'Shishe-Kab' pomegranates in response to salinity stress. Photosynthetica 52: 301-312, 2014.

Khayyat M., Tehranifar A., Davarynejad G.H., SayyariZahan M.H.: Effects of NaCl-salinity on some leaf nutrient concentrations, non-photochemical quenching and the efficiency of the PSII photochemistry of two Iranian pomegranate varieties under greenhouse and field conditions: Preliminary results. - J. Plant Nutr. 39: 1752-1765, 2016.

Lawlor D.W., Cornic G.: Photosynthetic carbon assimilation and associated metabolism in relation to water deficits in higher plants. - Plant Cell Environ. 25: 275-294, 2002.

Maas E.V., Hoffman G.J.: Crop salt tolerance - Current assessment. - J. Irr. Drain. Div.-ASCE 103: 115-134, 1977.

Mastrogiannidou E., Chatzissavvidis C., Antonopoulou C. et al.: Response of pomegranate cv. Wonderful plants to salinity. J. Soil Sci. Plant Nut. 16: 621-636, 2016.

Maxwell K., Johnson G.: Chlorophyll fluorescence: a practical guide. - J. Exp. Bot. 51: 659-668, 2000.

Melgarejo P.: [Varietal characterization of pomegranate (Punica granatum L.).] - Agrícola Vergel 12: 260-262, 1993. [In Spanish]

Meloni D.A., Oliva M.A., Martínez C.A., Cambraia J.: Photosynthesis and activity of superoxide dismutase, peroxidase and glutathione reductase in cotton under salt stress. Environ. Exp. Bot. 49: 69-76, 2003.

Morgan J.M.: Osmoregulation and water stress in higher plants. Ann. Rev. Plant Physio. 35: 299-319, 1984.

Munns R.: Comparative physiology of salt and water stress. Plant Cell Environ. 25: 239-250, 2002.

Naeini M.R., Khoshgoftarmanesh A.H., Fallahi E.: Partitioning of chlorine, sodium, and potassium and shoot growth of three pomegranate cultivars under different levels of salinity. J. Plant Nutr. 29: 1835-1843, 2006.

Nelson M.: A photometric adaptation of the Somogyi method for the determination of glucose. - J. Biol. Chem. 153: 375-380, 1944.

Okhovatian-Ardakani A., Mehrabanian M., Dehghani F., Akbarzadeh A.: Salt tolerance evaluation and relative comparison in cutting of different pomegranate cultivars. Plant Soil Environ. 56: 176-185, 2010.

Olmo-Vega A., García-Sánchez F., Simón-Grao S. et al: Physiological responses of three pomegranate cultivars under flooded conditions. - Sci. Hortic.-Amsterdam 224: 171-179, 2017.

Parihar P., Singh S., Singh R. et al.: Effect of salinity stress on plants and its tolerance strategies: a review. - Environ. Sci. Pollut. R. 22: 4056-4075, 2015.

Pourghayoumi M., Bakhshi D., Rahemi M. et al.: The physiological responses of various pomegranate cultivars to drought stress and recovery in order to screen for drought tolerance. Sci. Hortic.-Amsterdam 217: 164-172, 2017.

Rodrigues C.R.F.: [Effects of sodium chloride on growth and accumulation of castor bean nutrients.] $\mathrm{PhD}$ Thesis. Universidade Federal do Ceará, Fortaleza, 2007. [In Spanish]

Scholander P.F., Hammel H.T., Bradstreet E.D., Hemmingsen E.A.: Sap pressure in vascular plants. - Science 148: 339-346, 1965.

Shabala S., Munns R.: Salinity stress: physiological constraints and adaptive mechanisms. - In: Shabala S. (ed.): Plant Stress Physiology. Pp. 24-63. CABI, Wallingford 2017.

Somogyi M.: Note on sugar determination. - J. Biol. Chem. 195: 19-23, 1952.

Steppuhn H., van Genuchten M.T., Grieve C.M.: Root-zone salinity: II. Indices for tolerance in agricultural crops. - Crop Sci. 45: 221-232, 2005. 
Stolte J., Tesfai M., Øygarden L. et al.: Soil Threats in Europe: Status, Methods, Drivers and Effects on Ecosystem Services. Pp. 69-78. Office for Official Publications of the European Community, Luxembourg 2015.

Sun Y., Niu G., Masabni J.G., Ganjegunte G.: Relative salt tolerance of 22 pomegranate (Punica granatum) cultivars. HortScience 53: 1513-1519, 2018.
Syvertsen J.M., Garcia-Sanchez F.: Multiple abiotic stresses occurring with salinity stress in citrus. - Environ. Exp. Bot. 103: 128-137, 2014

Tattini M., Traversi M.L., Castelli S. et al.: Contrasting response mechanisms to root-zone salinity in three co-occurring Mediterranean woody evergreens: a physiological and biochemical study. - Funct. Plant Biol. 36: 551-563, 2009.

(C) The authors. This is an open access article distributed under the terms of the Creative Commons BY-NC-ND Licence. 